\title{
Clinical manifestations of optic pit maculopathy as demonstrated by spectral domain optical coherence tomography
}

This article was published in the following Dove Press journal:

Clinical Ophthalmology

17 January 2013

Number of times this article has been viewed

\author{
Jonathan H Tzu \\ Harry W Flynn Jr \\ Audina M Berrocal \\ William E Smiddy \\ Timothy G Murray \\ Yale L Fisher
}

Department of Ophthalmology, Bascom Palmer Eye Institute, University of Miami Miller School of Medicine, Miami, FL, USA
Correspondence: Harry W Flynn Jr 900 NW 17th Street, Miami,

FL 33।36, USA

$\mathrm{Tel}+13053266118$

Fax +I 3053266417

Email hflynn@med.miami.edu
Purpose: The purpose of this retrospective study was to evaluate the characteristic features, including spectral-domain optical coherence tomography (SD-OCT), clinical course, and outcome of treatment if given for patients with optic disc pit maculopathy.

Methods: We investigated a consecutive series of patients with a diagnosis of optic pit maculopathy treated between 2001 and 2012 at the Bascom Palmer Eye Institute. Patients were divided into two main groups, ie, patients who were observed without surgery and patients who received surgical intervention. The main outcome measures were presenting and final visual acuity, and changes in SD-OCT imaging were recorded. Other data including age, gender, eye, age of onset, length of follow-up, location of optic pit, and location of fluid by OCT were also recorded.

Results: On OCT, 67\% (12/18) of the eyes showed schisis-like cavities, 22\% (4/18) had only subretinal fluid, and $17 \%(3 / 18)$ had only a schisis-like cavity without subretinal fluid. In the patients managed by observation, visual acuity was $\geq 20 / 200$ in $6 / 8$ eyes initially and $6 / 8$ eyes at last follow-up. Ten of 18 patients received either focal laser, surgery or both. Six of 10 eyes undergoing surgery had initial visual acuity $\geq 20 / 200$, and 8 of 10 eyes undergoing surgery had a visual acuity of $\geq 20 / 200$ at last follow-up.

Conclusion: In this study, many eyes were observed and remained stable during follow-up. In eyes with reduced vision, surgical intervention produced variable outcomes, and persistent intraretinal/subretinal fluid was a common occurrence.

Keywords: optic pit maculopathy, spectral-domain optical coherence tomography

\section{Introduction}

First described by Wiethe in 1882, optic disc pits are small, gray-white, oval depressions found at the optic nerve head. ${ }^{1}$ Optic pits are a relatively rare clinical entity, with an estimated incidence of one in 11,000 people. Men and women are affected equally, and optic pits usually appear sporadically. ${ }^{2-4}$ They are usually found on the inferotemporal border of the optic nerve head, and $25 \%-75 \%$ of patients have macular involvement. ${ }^{4,8}$ Visual loss in patients with optic pits may be associated with retinoschisis and/or serous retinal detachment involving the macula.

Unanswered questions surrounding this condition include the origin of the macular fluid and the variable clinical features seen in individual patients. Although many reports have been published on the subject, the majority of publications are limited to case series and brief reports because of the rarity of this entity. ${ }^{5-7}$ Lincoff et al proposed that fluid from optic pits forms a schisis-like cavity in the retina initially, then progresses to a retinal hole in the outer layer and allows fluid to track subretinally. ${ }^{9}$ However, subsequent 
Table I Demographics and clinical characteristics

\begin{tabular}{|c|c|}
\hline \multicolumn{2}{|c|}{ Optic Pits 18 patients, 18 eyes } \\
\hline \multicolumn{2}{|l|}{$N=18$} \\
\hline Mean on presentation (years) & 27.9 (range 3-69) \\
\hline \multicolumn{2}{|l|}{ Gender } \\
\hline$M=$ male & $M=9$ \\
\hline$F=$ female & $F=9$ \\
\hline \multicolumn{2}{|l|}{ Laterality } \\
\hline $\mathrm{RE}=$ Right eye & $\mathrm{RE}=7$ \\
\hline LE $=$ Left eye & $\mathrm{LE}=\mathrm{II}$ \\
\hline Bilateral (patients) & $4 / 18$ \\
\hline \multirow[t]{3}{*}{ Location of pit } & Temporal $=7 / / 8$ \\
\hline & Inferotemporal $=9 / 18$ \\
\hline & Inferior $=2 / 18$ \\
\hline Median follow up (months) & 19.5 \\
\hline
\end{tabular}

optical coherence tomography (OCT) studies have shown serous detachment associated with optic disc maculopathy without schisis-like cavities. ${ }^{10-12}$

The purpose of the current study is to report a consecutive series of patients at a university referral center over a 10-year period, including presenting features, clinical course, and spectral-domain OCT documenting the status of the macula.

\section{Materials and methods}

The University of Miami institutional review board approved this retrospective study, which was conducted in accordance with the principles of the Declaration of Helsinki. The inclusion criteria were a diagnosis of optic disc pit and presentation between the years 2001 and 2011. All data were obtained via a retrospective chart review and entered into a standard computerized database for subsequent analysis. Patients were divided into two main groups, ie, patients with optic pit maculopathy who were observed without surgery and patients with optic pit maculopathy who received surgical intervention. The data collected included demographics (age and gender), visual acuity, surgical information, OCT findings, clinical characteristics of the optic pit, and complications. Patients without maculopathy, those who did not undergo OCT imaging, and those who had only one visit and no follow-up were excluded.

\section{Results}

In the current series of 18 eyes, the mean age of patients at diagnosis was 27.9 years. There were nine male and nine female patients. Four of the patients presented with bilateral optic nerve pits. Nine of 18 pits were inferotemporal, seven were temporal, and two were inferior. Median length of follow-up was 19.5 months (Table 1). The visual acuity of the patients who had optic pit maculopathy and were observed without surgery is shown in Table 2. Six of a total of eight patients had $\geq 20 / 200$ vision on presentation, which remained unchanged at the last follow-up. The average length of follow-up was 95.5 (range 3-310) months.

The visual acuity of 10 patients with optic pit maculopathy who had either surgery or laser is shown in Table 3. Of these 10 patients, two received only laser; six patients had $\geq 20 / 200$ visual acuity on presentation and eight had $\geq 20 / 200$ visual acuity at the last follow-up. The average length of follow-up was 71.6 (range 6-310) months. In the surgical group, persistent subretinal or intraretinal fluid occurred in four of seven patients. One patient had severe retinal pigment epithelium atrophy limiting postoperative visual acuity, and another patient developed a macular hole after surgery (Figure 6).

OCT findings for all the patients with optic pit maculopathy are described in Table 4. The location of the fluid was most often in the outer nuclear layer or in the subretinal space, although a significant portion of patients also had fluid in the inner nuclear layer. Twelve of 18 patients had a schisis-like cavity in the macula on OCT. Figures 1-6 shows

Table 2 Optic pit maculopathy observed without surgery

\begin{tabular}{|c|c|c|c|c|c|c|c|c|c|c|}
\hline Patient & Age & Gender & Eye & Location & $\begin{array}{l}\text { VA } \\
\text { (initial) }\end{array}$ & $\begin{array}{l}\text { VA } \\
\text { (last) }\end{array}$ & $\begin{array}{l}\text { Schisis- } \\
\text { like } \\
\text { cavity }\end{array}$ & $\begin{array}{l}\text { Location } \\
\text { of fluid } \\
\text { on OCT }\end{array}$ & $\begin{array}{l}\text { Length } \\
\text { of follow } \\
\text { up (months) }\end{array}$ & Comment \\
\hline I & 46 & $\mathrm{~F}$ & LE & Inferotemporal & $20 / 20$ & $20 / 20$ & Yes & $\begin{array}{l}\text { SRF, ONL, INL } \\
\text { GCL, SILM }\end{array}$ & 192 & \\
\hline 2 & 59 & $\mathrm{~F}$ & LE & Inferotemporal & $20 / 25$ & $20 / 25$ & Yes & ONL & 204 & \\
\hline 3 & 7 & $\mathrm{~F}$ & LE & Inferotemporal & $20 / 50$ & $20 / 80$ & No & SRF & 11 & \\
\hline 4 & 20 & $M$ & LE & Inferotemporal & $20 / 60$ & $20 / 70$ & No & SRF & 3 & \\
\hline 5 & 39 & $M$ & LE & Temporal & $20 / 200$ & $20 / 200$ & Yes & SRF, ONL & 24 & \\
\hline 6 & 23 & $M$ & LE & Inferotemporal & $20 / 200$ & $20 / 200$ & Yes & SRF, ONL & 4 & \\
\hline 7 & 65 & $M$ & LE & Inferior & $3 / 200$ & $1 / 200$ & No & None & 310 & $\begin{array}{l}\text { Significant RPE } \\
\text { atrophy }\end{array}$ \\
\hline 8 & 24 & M & RE & Inferior & $1 / 200$ & HM & Yes & SRF, ONL, INL & 16 & Chronic cystic RD \\
\hline
\end{tabular}

Abbreviations: SRF, subretinal fluid; ONL, outer nuclear layer; INL, inner nuclear layer; GCL, ganglion cell layer; SILM, sub-internal limiting membrane; VA, visual acuity; LE, left eye; RE, right eye; RPE, retinal pigment epithelium; RD, retinal detachment. 


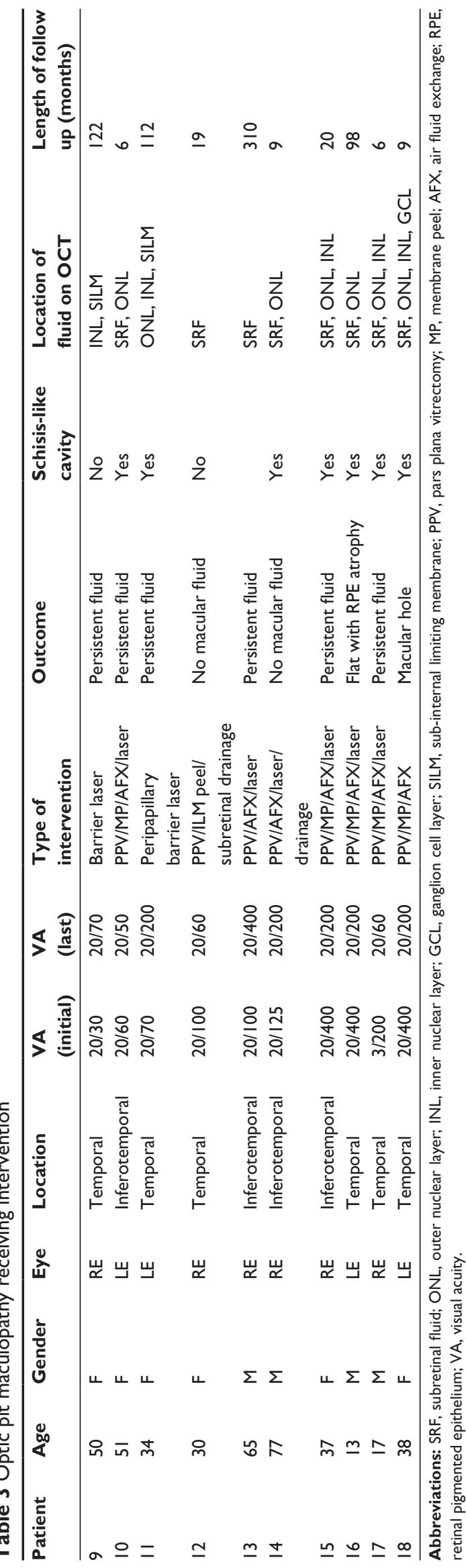

Table 4 Location of fluid for all optic pits with maculopathy on optical coherence tomography

\begin{tabular}{lllllll}
\hline $\mathbf{n = 1 7}$ & SRF & ONL & INL & GCL & SILM & $\begin{array}{l}\text { Schisis-like } \\
\text { cavity }\end{array}$ \\
\hline $\begin{array}{l}\text { Location } \\
\text { of fluid }\end{array}$ & $14 / 18$ & $12 / 18$ & $8 / 18$ & $3 / 18$ & $4 / 18$ & $12 / 18$ \\
\hline
\end{tabular}

Abbreviations: SRF, subretinal fluid; ONL, outer nuclear layer; INL, inner nuclear layer; GCL, ganglion cell layer; SILM, sub-internal limiting membrane.

the sequential OCT images of representative patients with varying clinical courses.

\section{Discussion}

Observational studies have shown that long-standing macular retinal detachment from optic pits is generally associated with poor visual acuity. ${ }^{13}$ Poor visual acuity

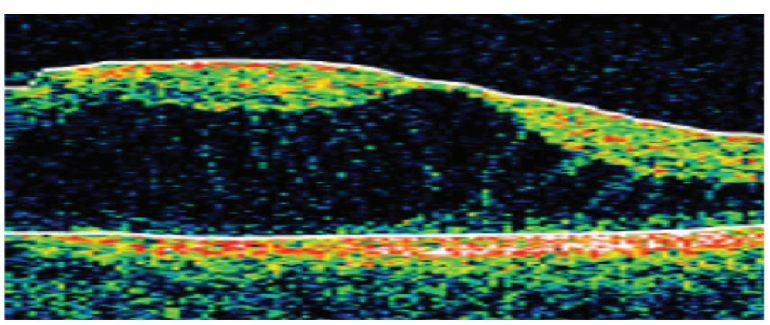

Jul 272005 BCVA 20/20

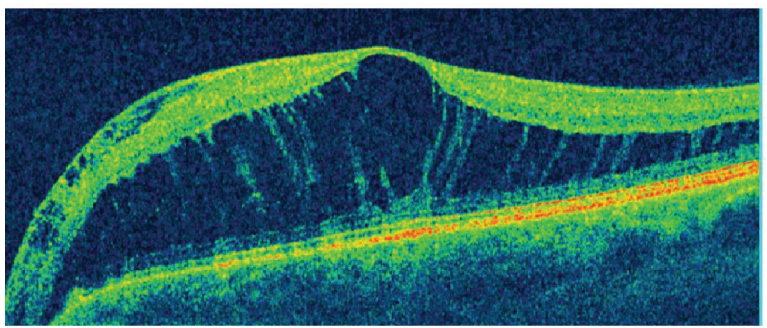

Feb 272009 BCVA 20/20
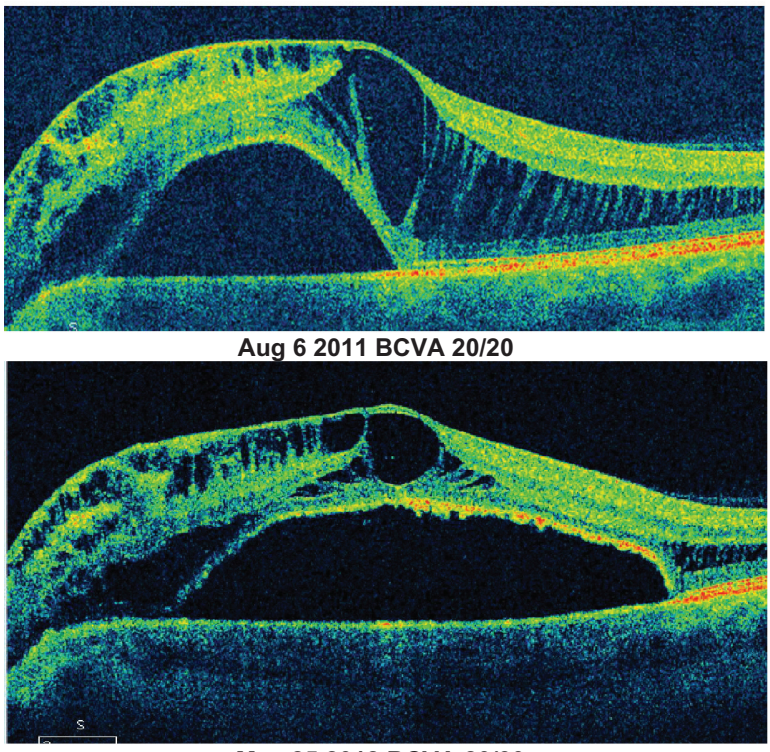

May 252012 BCVA 20/30

Figure I Observed patient with progression of schisis-like cavity over 6 year period. (Patient one, Table 2) 


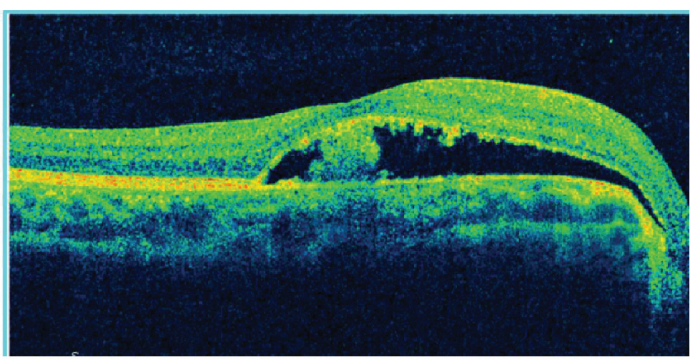

Feb 282011 BCVA 20/50

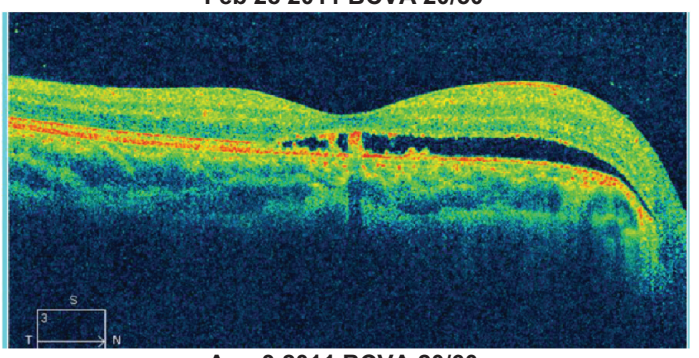

Aug 32011 BCVA 20/60

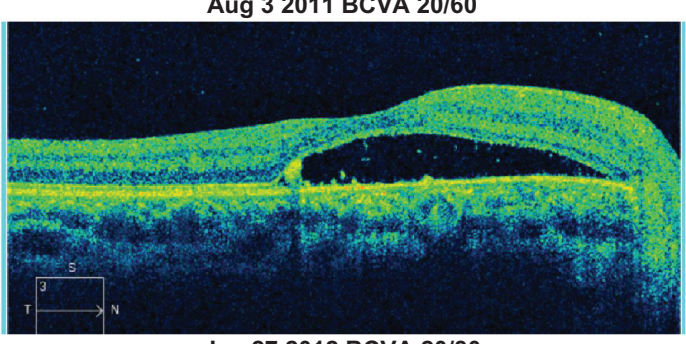

Jan 272012 BCVA 20/80

Figure 2 Observed patient with variable subretinal fluid over I year. (Patient 3, Table 2)

$(<20 / 200)$ on presentation is another predictor of poor visual outcome in these patients. In the observed patients, all with $\geq 20 / 200$ vision on presentation maintained that degree of vision over a reasonable follow-up duration. The patients who presented with poor vision $(<20 / 200)$ and were observed did not have visual improvement during

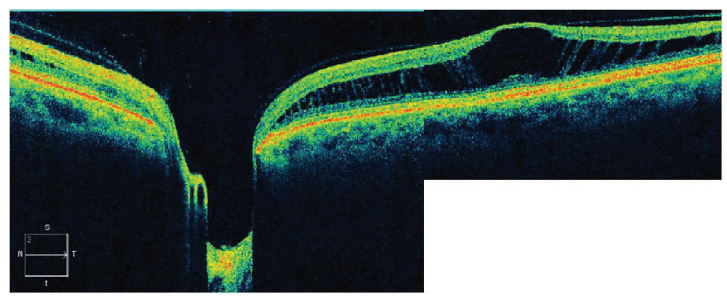

BCVA 20/25

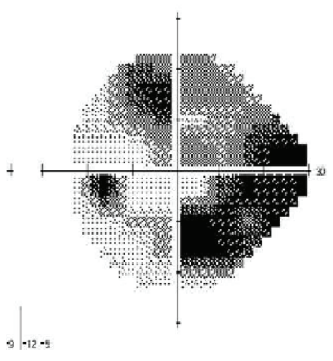

Figure 3 Observed patient with schisis cavity, and visual field deficit. (Patient 2, Table 2)

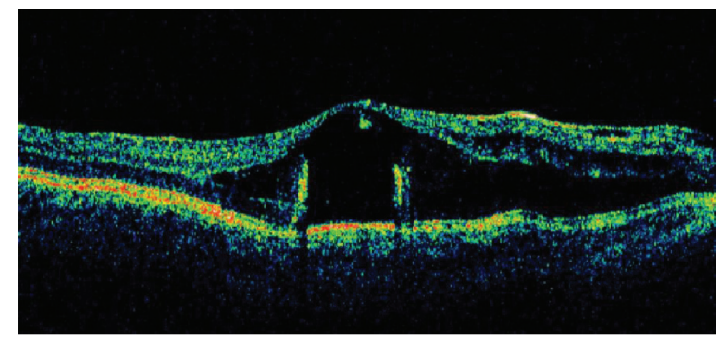

Preoperative BCVA 3/200 May 122008

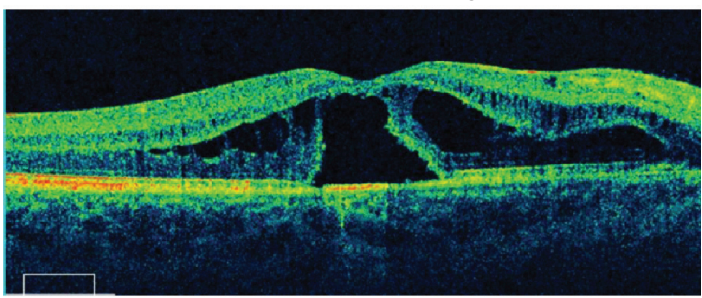

Postoperative month 4 BCVA 20/60 Oct 102008

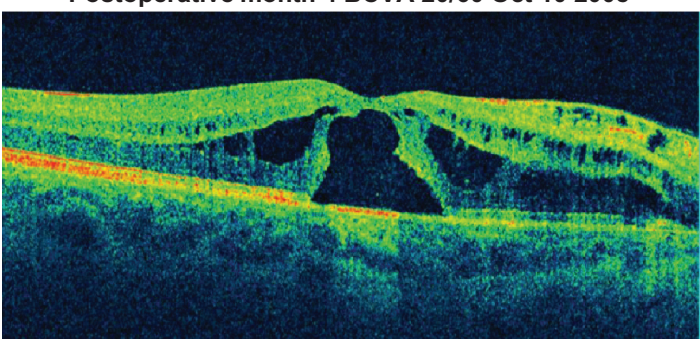

Postoperative month 6 BCVA 20/60 Dec 122008

Figure 4 Good visual recovery after surgery with persistent intraretinal fluid. (Patient 17, Table 3)

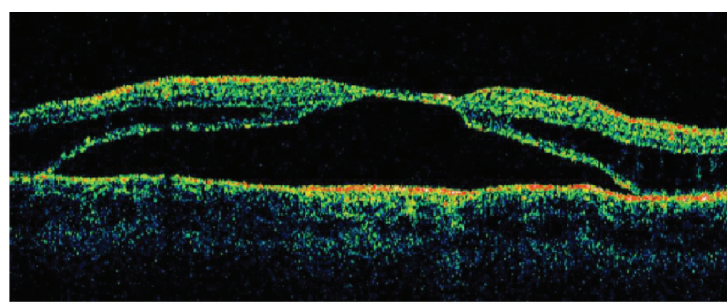

Preoperative BCVA 20/400 Dec 42002

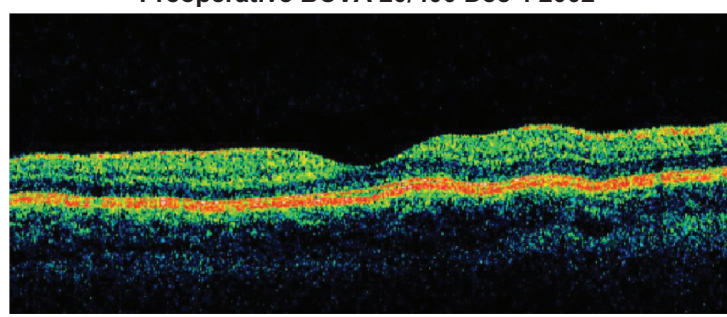

Postoperative month 4 BCVA 20/200 Apr 212002

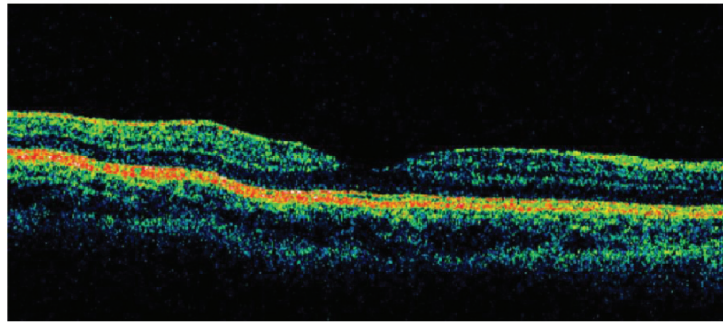

Postoperative year 5 BCVA 20/60 Apr 52007

Figure $\mathbf{5}$ Good visual recovery with good anatomic outcome. 


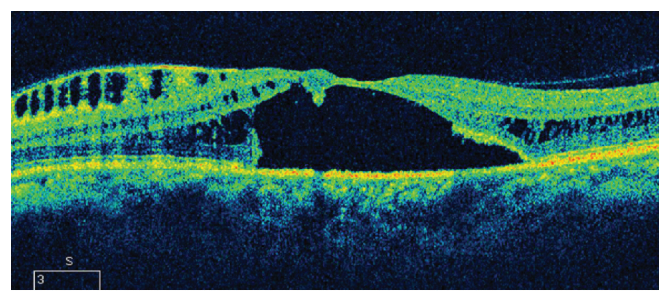

PreoperativeBCVA 20/400

Mar 22012

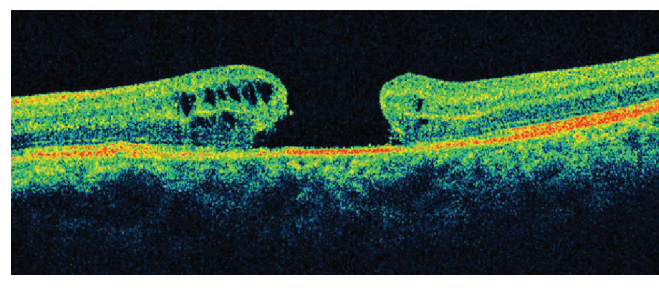

Postoperative month 1 BCVA 20/200

May 162012

Figure 6 Development of macular hole after surgery.

(Patient 18, Table 3)

follow-up. This is likely because of loss of photoreceptors which, in many cases, can be seen on SD-OCT. Figures 1 and 3 both show significant macular schisis cavities which were able to maintain 20/25 vision for greater than 10 years. This is likely because the schisis-like cavity had not affected the foveal center, and although they maintained excellent Snellen acuity, a visual deficit is seen in the visual field in Figure 3. However, in both of these cases, the schisis-like cavity remained stable over a long period with no significant changes.

SD-OCT findings in the observed group revealed many cases with schisis-like cavities, and also a number of cases with only subretinal fluid. SD-OCT studies of optic pits have shown that most cases of optic pit maculopathy have schisis-like cavities on SD-OCT. ${ }^{14}$ The fluid is most often observed in the outer nuclear layer, as described in prior OCT studies of optic pit maculopathy. However, macular fluid can be found in any of a number of layers. It is unclear if location of the fluid plays a role in how stable the vision will be if observed. The most common postoperative finding on OCT is persistent intraretinal or subretinal fluid, which may have limited the final visual acuity.

In the current series, many of the patients with optic pit maculopathy were observed. Surgical intervention had mixed benefit in the treatment of this rare condition. Variability in type of intervention may have contributed to the different visual and anatomical outcomes, and is certainly a limitation of this study. SD-OCT enables improved understanding of the anatomical changes and visual impact of optic pit maculopathy.

\section{Acknowledgments}

This work was supported in part by Research to Prevent Blindness, New York, NY, and a core grant from the National Eye Institute (P30-EY14801).

\section{Disclosure}

The authors report no conflicts of interest in this work.

\section{References}

1. Wiethe T. A case of optic nerve deformity. Arch Augenheilkd. 1882;11:14-19.

2. Reis W. A little known deformity of the optic nerve: circumscribed pit formation of the optic disc. Arch Augenheilk. 1908;19:505-528. German.

3. Halbertsma K. Crater-like hole and coloboma of the disc associated with changes at the macula. Br J Ophthalmol. 1927;11:11-17.

4. Kranenburg E. Crater-like holes in the optic disc and central serous retinopathy. Arch Ophthalmol. 1960;64:912-924.

5. Sugar HS. Congenital pits of the optic disc and their equivalents (congenital colobomas and colobomalike excavations) associated with submacular fluid. Am J Ophthalmol. 1967;63:298-307.

6. Gass JDM. Serous detachments of the macula secondary to congenital pit of the optic nerve head. Am J Ophthalmol. 1969;67:821-841.

7. Mustonen E, Varonen T. Congenital pit of the optic nerve head associated with serous detachment of the macula. Acta Ophthalmol. 1972; 50:689-698

8. Brown GC, Shields JA, Patty BE, Goldberg RE. Congenital pits of the optic nerve head. I. Experimental studies in collie dogs. Arch Ophthalmol. 1979;97:1341-1344.

9. Lincoff H, Lopez R, Kreissig I, Yannuzzi L, Cox M, Burton T. Retinoschisis associated with optic nerve pits. Arch Ophthalmol. 1988; 106:61-67.

10. Rutledge BK, Puliafito CA, Duker JS, Hee MR, Cox MS. Optical coherence tomography of macular lesions associated with optic nerve head pits. Ophthalmology. 1996;103:1047-1053.

11. Krivoy D, Gentile R, Liebmann JM, et al. Imaging congenital optic disc pits and associated maculopathy using optical coherence tomography. Arch Ophthalmol. 1996;114:165-170.

12. Lalwani GA, Punjabi OS, Flynn HW Jr, Knighton RW, Puliafito CA. Documentation optic nerve pit with macular schisis-like cavity by spectral domain OCT. Ophthalmic Surg Lasers Imaging. 2007;38: 262-264.

13. Brown GC, Shields JA, Goldberg RE. Congenital pits of the optic nerve head. II. Clinical studies in humans. Ophthalmology. 1980;87: $51-65$.

14. Imamura Y, Zweifel SA, Fujiwara T, Freund KB, Spaide RF. High-resolution optical coherence tomography findings in optic pit maculopathy. Retina. 2010;30:1104-1112. 


\section{Publish your work in this journal}

Clinical Ophthalmology is an international, peer-reviewed journal covering all subspecialties within ophthalmology. Key topics include: Optometry; Visual science; Pharmacology and drug therapy in eye diseases; Basic Sciences; Primary and Secondary eye care; Patient Safety and Quality of Care Improvements. This journal is indexed on
PubMed Central and CAS, and is the official journal of The Society of Clinical Ophthalmology (SCO). The manuscript management system is completely online and includes a very quick and fair peer-review system, which is all easy to use. Visit http://www.dovepress.com/ testimonials.php to read real quotes from published authors. 